\title{
Effect of Inherent Anatomy of Plant Fibers on the Morphology of Carbon Synthesized from Them and Their Hydrogen Absorption Capacity
}

\author{
Madhuri Sharon*and Maheshwar Sharon \\ N.S N. Research Center for Nanotechnology and Bio-Nanotechnology, Jambhul Phata, SICES College, Ambernath (W), 421 504, \\ Maharashtra, India
}

\section{Article Info}

Received 23 March 2012

Accepted 15 May 2012

*Corresponding Author

E-mail: sharonmadhuri@gmail.com

Tel: +91-9552599207

\section{Open Access}

DOI: http://dx.doi.org/

10.5714/CL.2012.13.3.161

This is an Open Access article distributed under the terms of the Creative Commons Attribution Non-Commercial License (http://creativecommons.org/licenses/ by-nc/3.0/) which permits unrestricted non-commercial use, distribution, and reproduction in any medium, provided the original work is properly cited.

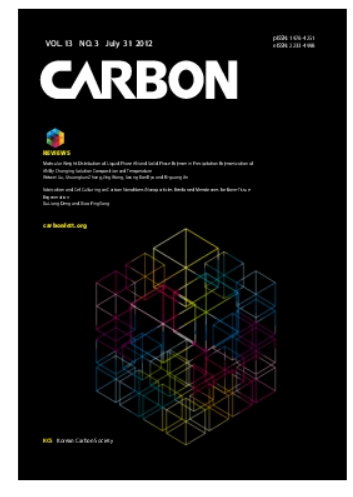

http://carbonlett.org

pISSN: 1976-4251

elSSN: 2233-4998

Copyright $\odot$ Korean Carbon Society

\begin{abstract}
Carbon materials were synthesized by pyrolysis from fibers of Corn-straw (Zea mays), Ricestraw (Oryza sativa), Jute-straw (Corchorus capsularis) Bamboo (Bombax bambusa), Bagass (Saccharum officinarum), Cotton (Bombax malabaricum), and Coconut (Cocos nucifera); these materials were characterized by scanning electron microscope, X-ray diffraction (XRD), and Raman spectra. All carbon materials are micro sized with large pores or channel like morphology. The unique complex spongy, porous and channel like structure of Carbon shows a lot of similarity with the original anatomy of the plant fibers used as precursor. Waxy contents like tyloses and pits present on fiber tracheids that were seen in the inherent anatomy disappear after pyrolysis and only the carbon skeleton remained; XRD analysis shows that carbon shows the development of a (002) plane, with the exception of carbon obtained from bamboo, which shows a very crystalline character. Raman studies of all carbon materials showed the presence of G- and D-bands of almost equal intensities, suggesting the presence of graphitic carbon as well as a disordered graphitic structure. Carbon materials possessing lesser density, larger surface area, more graphitic with less of an $\mathrm{sp}^{3}$ carbon contribution, and having pore sizes around $10 \mu \mathrm{m}$ favor hydrogen adsorption. Carbon materials synthesized from bagass meet these requirements most effectively, followed by cotton fiber, which was more effective than the carbon synthesized from the other plant fibers
\end{abstract}

Key words: carbon material, hydrogen adsorption, pyrolysis, plant fibers

\section{Introduction}

There have been many attempts at synthesizing nano and micro carbon material from plant derived precursors by pyrolysis. In their effort to obtain different types of carbon nano materials (CNMs), Sharon's group [1-7] screened plant derived materials like oils, seeds, volatile oils, resins, and fibrous plant tissues, etc.; each material resulted in a different carbon morphology.

Plant fibers are mature xylem tissues, which can help in water and mineral translocation. They are complex permanent dead tissue, made up of four different types of cellular elements, i.e. tracheids, tracheae, fibers, and xylem parenchyma (parenchyma is the only living component of the tissue).

Plant fibers are composed of long narrow tapering cells, also known as Sclerenchyma cells (Fig. 1). They are dead and hollow at maturity, having thick cell walls composed mostly of cellulose and lignin. Fibers are rigid and provide support and occur in many different shapes and sizes, but two main types occur: fibers and sclereids. Fibers are greatly elongated (many times longer than they are wide) cells whose long, tapering ends interlock, thus providing maximum support to a plant. The side walls of fibers are often so thick that the center of the cell (the lumen) is often occluded. Fibers have great tensile strength and yet are also 
1<smiles>CC(O)C=Cc1ccc(O)cc1</smiles>

2<smiles>COc1cc(C=CCO)ccc1O</smiles>

3<smiles>COc1cc(/C=C/CO)cc(OC)c1O</smiles>

Fig. 1. Molecular structure of LIGNIN having three common mono-lignols [(1) Paracoumaryl alcohol, (2) Coniferyl alcohol and (3) Sinapyl alcohol]

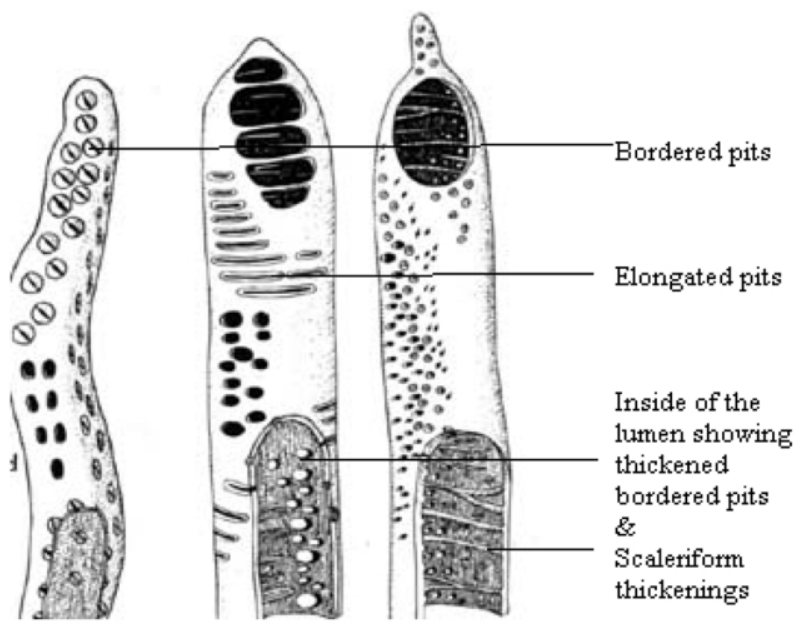

Fig. 2. Schematic diagram of tracheids from different angles.

elastic. These qualities are significant in the flexible support of the plants. Lumen is spacious and extends throughout the length of the tracheid. In some cases, due to the deposition of lignin, the primary wall develops numerous concave depressions called pits, which give the tracheids very special, different morphologies.

Cellulose is the major component of rigid plant cell walls Cellulose is a linear polysaccharide polymer containing many Beta glucose monosaccharide units. Unlike a starch, in cellulose the acetal linkage is beta. Alpha glucose is also the monomer unit in cellulose.

Lignin is formed by the removal of hydroxyl groups from sugars (it is an irreversible reaction), creating phenolic compounds and short-chain alcohol ligands. Lignin polymers are heavily cross-linked. It is difficult to define the precise structure of lignin as a chemical molecule. There is great variation in the chemical composition of lignin, even within the same plant. The basic monomer of lignin is 4-alkylcatechol.

The present work is an attempt to study the morphology of CNM obtained from various plant fibers and to compare them with the inherent anatomy of the plant fibers from which they were synthesized.

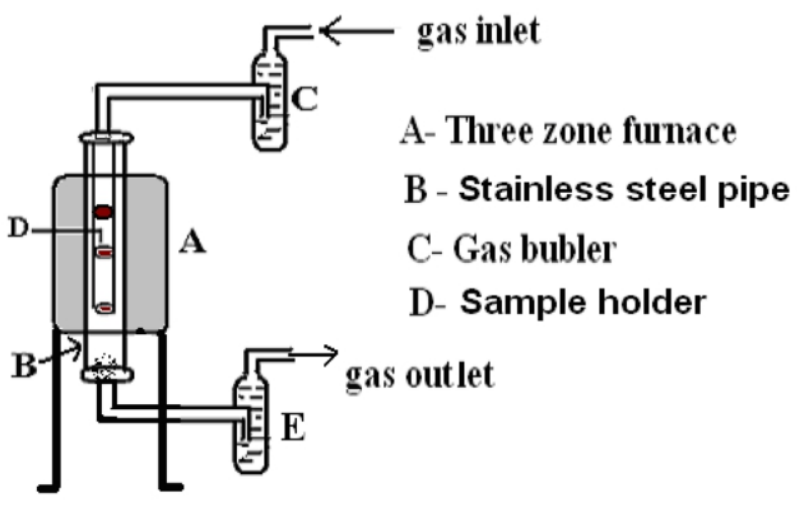

Fig. 3. Schematic diagram of apparatus used for pyrolysis of fibrous plant materials.

\section{Experimental}

\subsection{Sample preparation}

2.1.1. Synthesis of carbon from plant fibers

Different types of plant fibers i.e. Corn-straw (Zea mays), Rice-straw (Oryza sativa), Jute-straw (Corchorus capsularis), Bamboo (Bombax bambusa), Bagass (Saccharum officinarum), Semur cotton (Bombax malabaricum), and Coconut (Cocos nucifera) were dried in an oven at $100^{\circ} \mathrm{C}$ for $6 \mathrm{~h}$ to remove moisture. Since bagass has a waxy coating and a strong cuticular layer, it was first soaked in $8 \mathrm{M} \mathrm{KOH}$ solution for $24 \mathrm{~h}$ and then washed several times with water till water it showed a neutral $\mathrm{pH}(\sim 7.5)$; it was then dried in an oven at $100^{\circ} \mathrm{C}$.

For pyrolysis, a vertical electrical stainless steel furnace of 3 KW was used (Fig. 2). In this furnace, a 1 meter stainless steel tube (B) of $10 \mathrm{~cm}$ diameter was inserted. Inside this tube there were three holders, one in each furnace zone, to hold metallic boats that contained the plant material for pyrolysis. Chopped fibrous plant material (50-100 g) was kept in the boat and then inserted into the holder (D) in the furnace. To flush out air from the furnace (E), nitrogen gas was flowed in (C) at a flow rate of $100 \mathrm{~cm}^{3} \mathrm{~min}^{-1}$ to create an inert atmosphere. After flowing the gas for $5 \mathrm{~min}$, the furnace temperature was set at $850^{\circ} \mathrm{C}$ in order to pyrolize the plant material. Once the furnace reached the desired temperature, the heating was continued for a further $3 \mathrm{~h}$ at constant set temperature and then the furnace was allowed to cool down to room temperature. The carbon material was collected from the boat (D).

The synthesized carbon contained some amorphous carbon, which was removed by soaking samples in $12 \mathrm{M}$ nitric acid (72 $\%$ pure) followed by soaking in $10 \mathrm{M}$ hydrochloric acid (40\% pure) for $30 \mathrm{~min}$. Then, samples were filtered. The acid treated carbons were repeatedly washed with distilled water until the water showed a neutral $\mathrm{pH}$ (6.5-7.0); samples were then filtered. Finally, samples were rinsed with acetone to remove the water and then dried in an oven at $150^{\circ} \mathrm{C}$ for $24 \mathrm{~h}$

2.1.2. Characterization of carbon materials

This process was carried out by scanning electron microscope (SEM) using FEI Quanta 2 (prior to pyrolysis, SEM micrographs 
of plant fibers were also taken), X-ray diffraction (XRD, using a Philips Panalytical Xpert with $\mathrm{K} \alpha$ of $\mathrm{Cu}(0.154056)$ ), and Raman spectra.

2.1.3. Hydrogen adsorption study by these carbons

The methodology used was the same as described in various presentations of Sharon's group $[1,2]$

\section{Results and Discussion}

Materials collected from the boats (D) kept inside the furnace were used for characterization. Pyrolysis of lignin (wood) is known to produce charcoal and a range of other products,

\subsection{SEM analysis}

All carbon materials were of micro size, having large pores and channel like structures

Plant fibers are made up of thick walled sclerenchymatous tissues, trachea, tracheids, and xylem vessels having primary thickening on their walls and phloem fibers. These fibrous tissues have elongated cells with thickened walls. Under SEM in cross sectional view, they show pore like structures, whereas in longitudinal or vertical sectional view they show clear channel like structures.

Since there is a great variation in the chemical composition of lignin, the structure of tracheids and trachea show different types of thickening; even within the same plant, each type of plant material showed slight variation in anatomical structure Therefore, CNM prepared from plant fibers also showed similar channel like structures, which in cross sectional view gives an appearance of a porous, sponge like entity (Fig. 4).

All the carbon samples show a structure that resembles the tissue structure of the plant material from which they were synthesized. It appears as if, except for the carbon, all the other ingredients, e.g. tyloses present on the surface of the plant tissues and thickening on the cell walls of the tracheids, have sublimed, leaving the carbon skeleton intact. From a study of the series of electron micrographs of the primary xylem cells at various stages of development, it can be suggested that the microtubules are instrumental for the localized thickening of the tracheids [8]. This may account for the presence of a microtubular morphology in the carbonized plant fibers.

\subsection{XRD characterization}

XRD images of carbon materials prepared by the pyrolysis of various precursors are shown in Fig. 5. The characteristic planes for each carbon material are shown in the spectra. If we compare the XRD presented in Fig. 5 with that of the pure carbon nanotube (CNT) [9-12] and pure carbon nanofiber (CNF) [13], presented in Fig. 6, we can see that these images show that CNT has peaks at $26.4^{\circ}, 43^{\circ}, 53^{\circ}$, and $78^{\circ}$ for (002), (111), (200), and (311) planes, respectively, whereas CNF shows peaks at $26.4^{\circ}$, $42^{\circ}$, and $62^{\circ}$ for $(002),(100)$, and (103) planes, respectively. This comparison suggests that XRD for CNT has a very sharp peak for (002) while CNF has a broad peak. Accordingly, it can be concluded that carbon materials obtained from these precursors

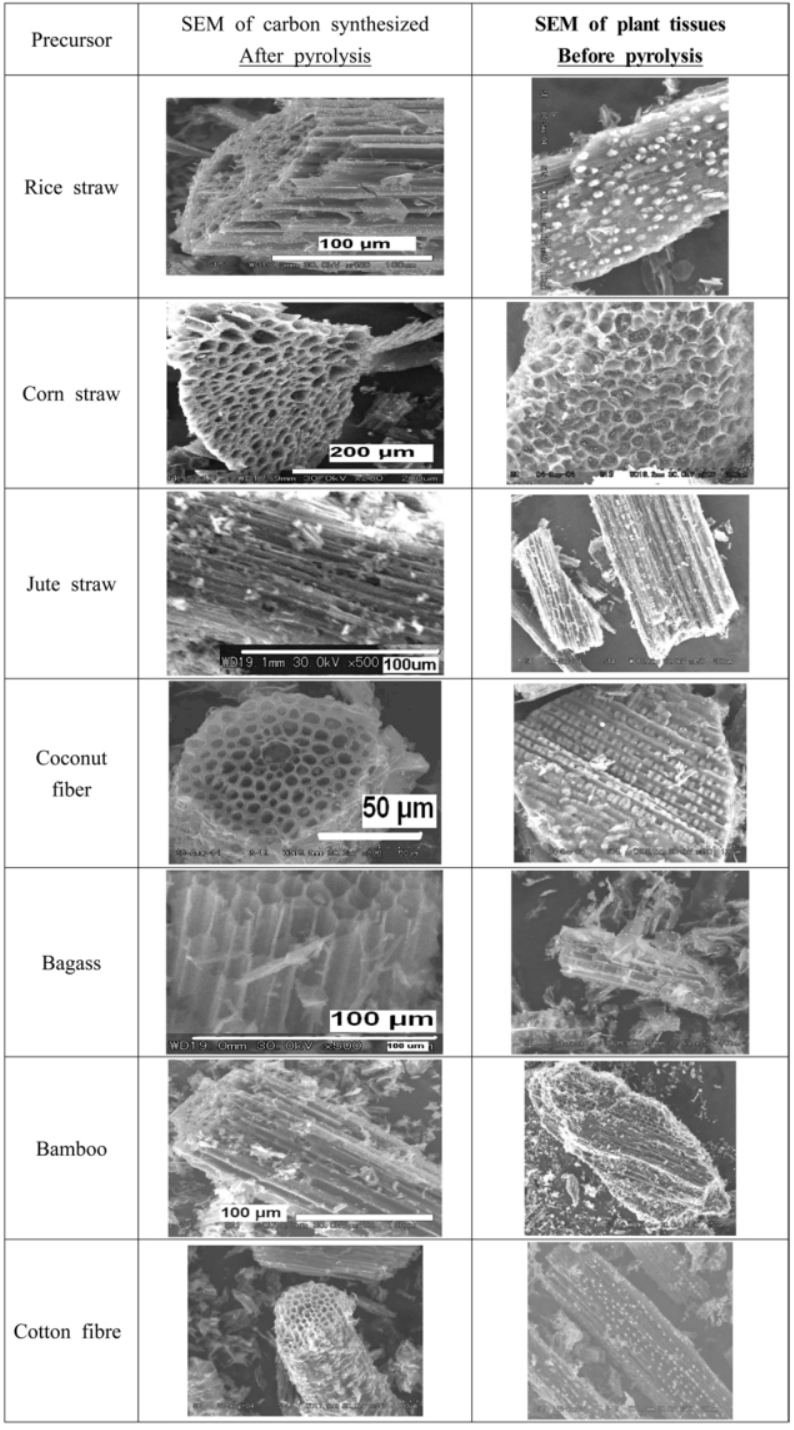

Fig. 4. Scanning electron microscope (SEM) of plant tissues and corresponding carbon synthesized from them.

possess characters similar to those of $\mathrm{CNF}$, rather than those of CNT. However, confirmatory tests can only be obtained from the transmission electron microscope studies. The broadened (100) and (103) peaks reflect the disordered graphitic character. All the carbon obtained from fibrous plant materials shows the development of a (002) plane, with the exception of carbon obtained from bamboo, which shows a very crystalline character.

\subsection{Characterization by micro-Raman spectroscopy}

Raman spectra of carbon materials synthesized from various fibrous precursors were taken over a broad frequency range using $E_{\text {laser }}=785 \mathrm{~nm}=1.58 \mathrm{eV}$ excitation. Each of the materials showed the presence of D-bands and G-bands. Their peak positions were not at the same positions as one would obtain from pure graphite or diamond. The ratio of the intensity of the G-bands and the D-bands were calculated from each graph obtained from each type of carbon material. Details of the Raman spectra and the 


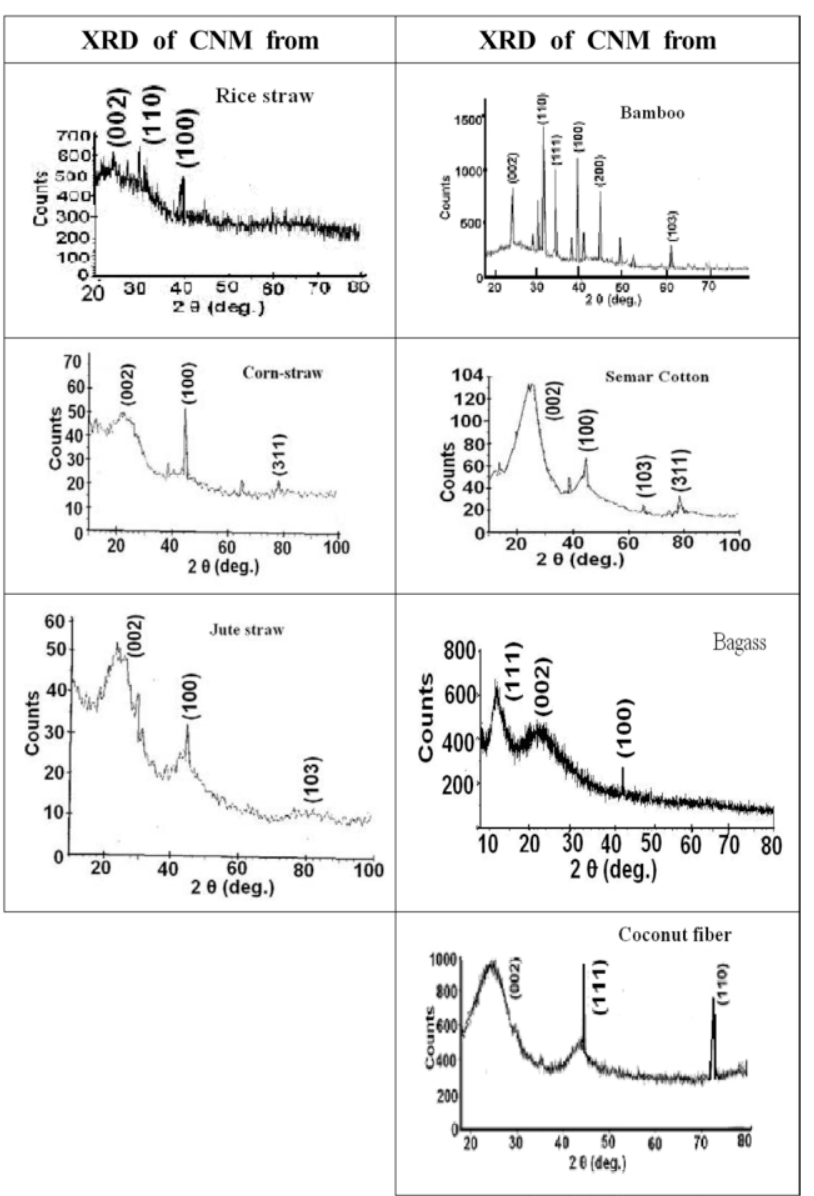

Fig. 5. X-ray diffraction (XRD) of carbon nano materials (CNM) synthesized from various fibrous plant materials.

positions of the D-bands and G-bands are shown in Fig. 6; and, for comparison, Raman spectra of am orphous carbon, diamond, graphite, and CNT are shown in Fig. 6.

The Raman peaks at $1580 \mathrm{~cm}^{-1}$ in both samples (i.e. CNT and graphite) are attributed to the tangential stretching $\mathrm{G}$ mode. The peak at $1400 \mathrm{~cm}^{-1}$ is attributed to the disorder-in-

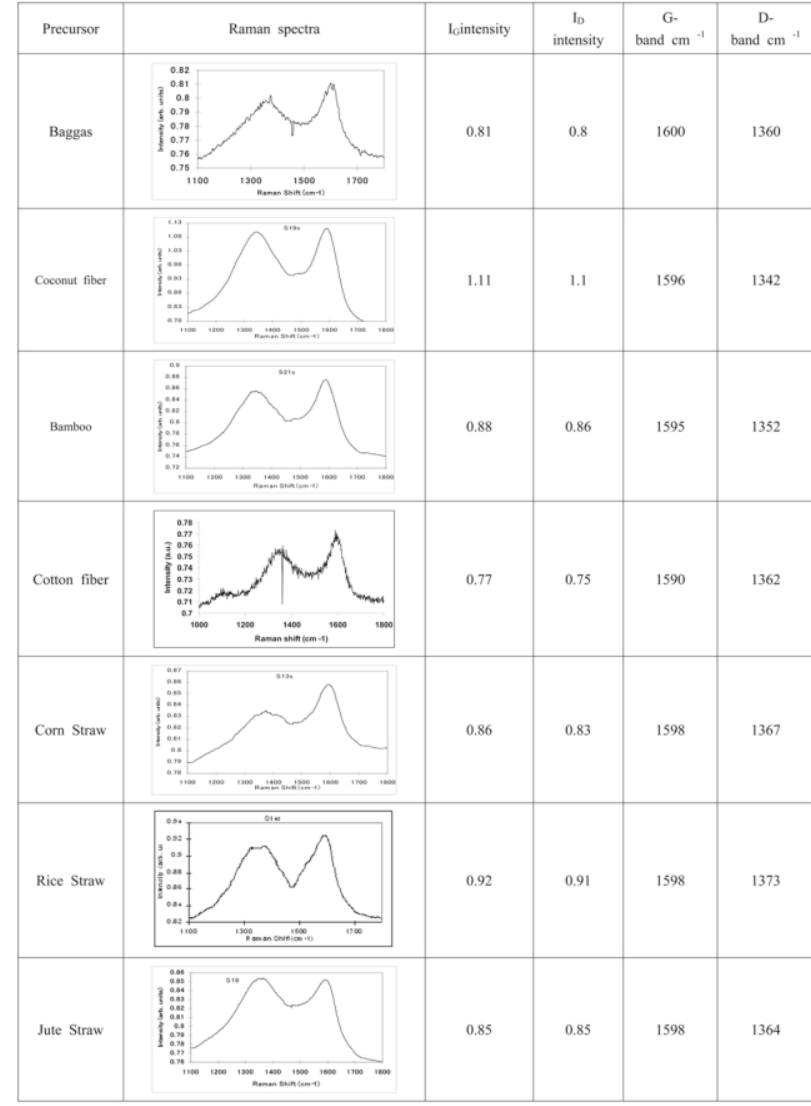

Fig. 7. Raman spectra of carbon synthesized from various fibrous plant materials.

duced D mode, which did not occur in the Raman spectrum of the graphite stock. The appearance of a D band is due to defects on the CNT or to amorphous carbon in the product, which shows the graphitization degree of the product. The Raman spectrum of all carbon materials (Fig. 7) shows the presence of G- and D-bands. Their positions are shifted more towards the higher wave number (i.e. more towards the G-band obtained for the highly ordered pyrolytic graphite [HOPG]).
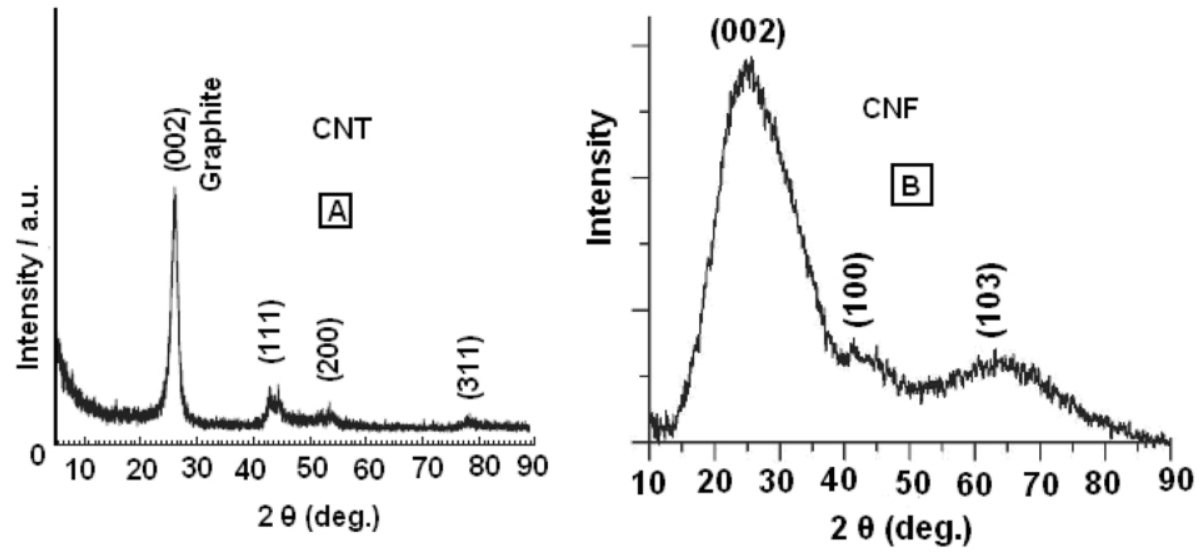

Fig. 6. X-ray diffraction of (A) carbon nanotubes (CNTs) showing (002) plane of graphite (Du et al., 2008 and Chen et al., 2005) and (B) carbon nanofibers (CNFs) showing (002) plane of graphite [13]. 
(A)

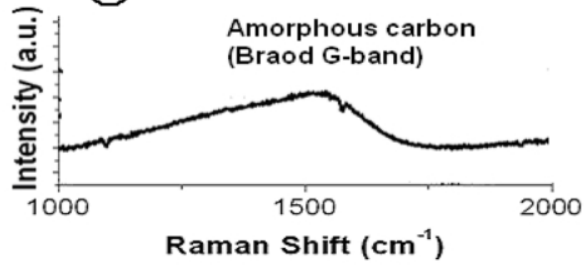

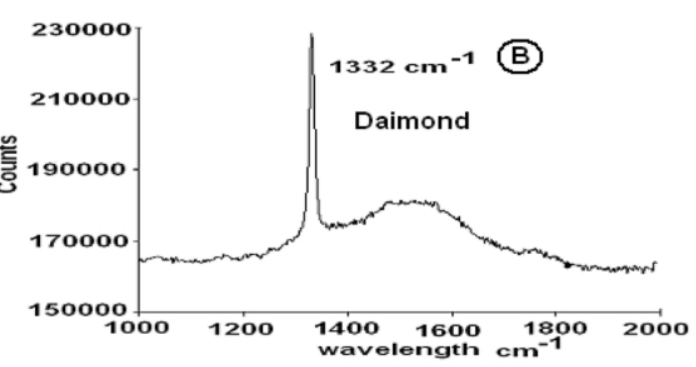

wavelength $\mathrm{cm}^{-1}$

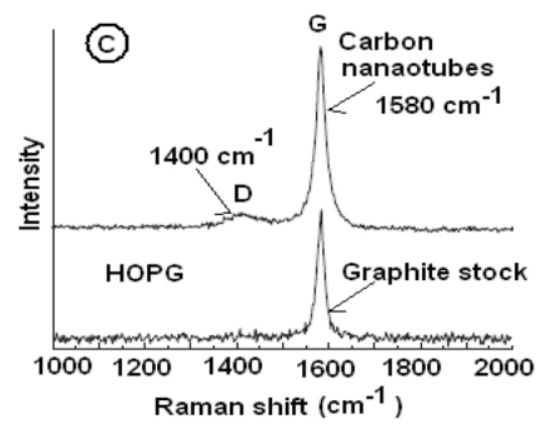

Fig. 8. Raman spectra of (a) amorphous carbon film [Ferrari et al., 2000][14] showing a overlapping with a broad G-band and D-band. (b) Diamond showing a sharp D-band [15] and (c) showing intense G-band and small hump of D-band obtained via CNT and intense peak of G-band for highly ordered pyrolytic graphite (HOPG) [Chen et al., 2005] [12].

\section{Table 1. Hydrogen adsorption and various properties of carbon materials prepared from different plant materials}

\begin{tabular}{|c|c|c|c|c|c|c|c|}
\hline Precursors & Pore size $(\mu \mathrm{m})$ & Density (g/cc) & D-band $\left(\mathrm{cm}^{-1}\right)$ & G-band $\left(\mathrm{cm}^{-1}\right)$ & $\mathrm{I}_{\mathrm{G}} / \mathrm{I}_{\mathrm{D}}$ & $\begin{array}{c}\text { Surface area } \\
\left(\mathrm{m}^{2} / \mathrm{g}\right)\end{array}$ & $\begin{array}{l}\text { Hydrogen-adsorption } \\
\text { at } 11 \mathrm{~kg} / \mathrm{m}^{2} \mathrm{wt} \%\end{array}$ \\
\hline Bagass & 10.12 & 0.225 & 1373 & 1603 & 1.020 & 187.66 & 2.095 \\
\hline Jute & 1.26 & 0.222 & 1364 & 1598 & 1.000 & 100.96 & 0.345 \\
\hline Rice straw & 6.84 & 0.277 & 1356 & 1597 & 1.017 & 140.15 & 0.182 \\
\hline Bamboo & 8.14 & 0.46 & 1349 & 1592 & 1.002 & 12.83 & 0.526 \\
\hline Corn stem & 6.05 & 0.646 & 1383 & 1594 & 1,074 & 61.25 & 0.372 \\
\hline Coconut fiber & 6.38 & 0.3 & 1345 & 1594 & 1.018 & 55.59 & 0.876 \\
\hline
\end{tabular}

Almost all CNMs showed almost equal intensities of G- and D-bands, with slight variations. Band intensities were in the range of 0.7 to 0.9

Our findings on the characteristics of CNM prepared from fibrous plant materials show that since these were complex precursors having different types of chemical compounds, the pyrolyzed product yielded lots of impurities along with amorphous carbon, and hence acidic purification was needed. So far as the morphology of the carbon is revealed from the SEM studies, it is considered that the complex morphological nature can be attributed to the nature of the morphology of the precursors. All the carbons had a (002) plane shift towards the lower angle of $26.4^{\circ}$. Raman studies of all CNMs showed the presence of G-and D-bands of almost equal intensity, suggesting the presence of graphitic carbon as well as a disordered graphitic structure.

3.3.1. Hydrogen absorption capacity of carbons synthesized from different precursors

Hydrogen adsorption capacity and various properties of carbon materials prepared from three plant materials, which showed promising results, were compared and are presented in Table 1 .

Table 1 shows that carbon materials possessing lesser density, larger surface area, more graphitic structure with less of an $\mathrm{sp}^{3}$ carbon contribution, and having pore sizes of around $10 \mu \mathrm{m}$ favor hydrogen adsorption. Carbon materials synthesized from bagass meet these requirements more effectively than materials fabricated from other types of carbon material. The second most effective carbon material was that prepared from cotton.

\section{Conclusions}

Plant fibers, being rich sources of carbon and hav ing different inherent plant structures, have yielded carbons with different morphologies. Depending on their available surface area and density, they have shown differences in their capacity to adsorb hydrogen gas. These findings on hydrogen adsorption capacity, 
and an analysis of the morphology of the carbon material synthesized from different plant fibers, open a new possibility of correlating the finer structure of the synthesized carbon and their various applications. Such studies would help in the future in synthesizing desired types of carbon material from waste plant material for use in different applications.

\section{References}

[1] Sharon M, Soga T, Afre R, Sathiyamoorthy D, Dasgupta K, Bhardwaj $\mathrm{S}$, Sharon M, Jaybhaye S. Hydrogen storage by carbon materials synthesized from oil seeds and fibrous plant materials. Int J Hydrogen Energy, 32, 4238 (2007). http://dx.doi.org/10.1016/j. ijhydene.2007.05.038.

[2] Sharon M, Bhardwaj S, Jaybhaye S, Sathiyamoorthy D, Dasgupta K, Sharon M. Hydrogen adsorption by carbon nanomaterials from natural source. Asian J Exp Sci, 22, 75 (2008).

[3] Khairnar V, Jaybhaye S, Hu CC, Afre R, Soga T, Sharon M, Sharon M. Development of super capacitor using carbon material synthesized from plant derived precursors. Carbon Lett, 9, 188 (2008).

[4] Bhardwaj S, Jaybhaye S, Sharon M, Sathiyamoorthy D, Dasgupta K, Jagadale P, Gupta A, Patil B, Oza G, Pandey S, Soga T, Afre R, Kalita G, Sharon M. Carbon nanomaterials from tea leaves as an anode in lithium secondary batteries. Asian J Exp Sci, 22, 89 (2008).

[5] Bhardwaj S, Sharon M, Ishihara T, Jayabhaye S, Afre R, Soga T, Sharon M. Carbon material from natural sources as an anode in lithium secondary battery. Carbon Lett, 8, 285 (2007).

[6] Jagadale P, Sharon M, Sharon M, Kalita G. Carbon thin films from plant-derived precursors. Synth React Inorg Metal-Org Nano-Metal Chem, 37, 467 (2007). http://dx.doi.org/10.1080/ 15533170701471588 .
[7] Kshirsagar DE, Puri V, Sharon M, Sharon M. Microwave absorption study of carbon nano material, synthesized from natural oils Carbon Lett, 7, 245 (2006)

[8] Maitra SC, De DN. Role of microtubules in secondary thickening of differentiating xylem element. J Ultrastruct Res, 34, 15 (1971). http://dx.doi.org/10.1016/s0022-5320(71)90003-7.

[9] Du CY, Zhao TS, Yang WW. Effect of methanol crossover on the cathode behavior of a DMFC: a half-cell investigation. Electrochim Acta, 52, 5266 (2007). http://dx.doi.org/10.1016/j.electacta.2007.01.089.

[10] Du Gx, Kang Zr, Song Jl, Zhao Jh, Song C, Zhu Zp Theoretical and experimental evidence of a metal-carbon synergism for the catalytic growth of carbon nanotubes by chemical vapor deposition New Carbon Mater. 23(4): 331-338 (2008). DOI: 10.1016/S18725805(09)60004-4

[11] Chen X.H, C.S. Chen, H.N. Xiao, F.Q. Cheng, G. Zhang, G.J. Yi Corrosion behavior of carbon nanotubes-Ni composite coating, Surf. Coat . Technol. 191, 351-356 (2005). DOI: 10.1016/j.surfcoat.2004.04.055.

[12] Chen $\mathrm{CH}$, Huang CC. Hydrogen storage by KOH-modified multiwalled carbon nanotubes. Int J Hydrogen Energy, 32, 237 (2007). http://dx.doi.org/10.1016/j.ijhydene.2006.03.010.

[13] Hsieh CT, Chen JM, Lin HH, Shih HC. Field emission from various CuO nanostructures. Appl Phys Lett, 83, 3383 (2003). http:/ dx. doi.org/10.1063/1.1619229

[14] Ferrari AC, Robertson J. Interpretation of Raman spectra of disordered and amorphous carbon. Phys Rev B, 61, 14095 (2000) http://dx.doi.org/10.1103/PhysRevB.61.14095.

[15] Muller-Sebert W, Worner E, Fuchs F, Wild C, Koidl P. Nitrogen induced increase of growth rate in chemical vapor deposition of diamond. Appl Phys Lett, 68, 759 (1996). http://dx.doi org/10.1063/1.116733 